\title{
Influence of laser power on tensile properties and material characteristics of laser-sintered UHMWPE
}

\author{
Yas Khali1 ${ }^{1, *}$, Adam Kowalski ${ }^{2}$, and Neil Hopkinson ${ }^{1,3}$ \\ 1 Department of Mechanical Engineering, The University of Sheffield, Sheffield S1 3JD, UK \\ 2 Unilever, R\&D Port Sunlight Laboratory, Wirral CH63 3JW, UK \\ 3 XAAR plc, Cambridge Science Park, Cambridge, CB4 0XR, UK
}

Received 8 January 2016 / Accepted 4 September 2016

\begin{abstract}
Ultra High Molecular Weight Polyethylene (UHMWPE) has excellent properties, such as high mechanical performance, low friction, high wear and chemical resistance but so far there has been limited use in additive manufacturing (AM). Laser sintering of polymers is one of the most promising AM technologies due to its ability to produce complex geometries with accurate dimensions and good mechanical properties. Consequently, this study investigates the influence of laser power on physical and mechanical properties of UHMWPE parts produced by laser sintering. In particular mechanical properties, such as Ultimate Tensile Strength (UTS), Young's Modulus and elongation at break were evaluated alongside relative density, dilation and shrinkage. Finally, the fracture surface of the tensile test specimens was examined by electron microscopy. Results show that within a laser power range of 6-12 W there appears to be an optimum where tensile strength and relative density reach a maximum, dilation is minimised and where elongation increases with laser power. UTS up to $2.42 \mathrm{MPa}$, modulus up to $72.6 \mathrm{MPa}$ and elongation at break up to $51.4 \%$ were observed. Relative density and part dimensions are also influenced by laser power.
\end{abstract}

Key words: Additive manufacturing, UHMWPE, Laser sintering, Laser power, Tensile properties

\section{Introduction}

\subsection{Laser sintering}

Laser Sintering (LS) is an additive manufacturing (AM) technique in which parts are built layer by layer using laser to sinter powdered material directly from three-dimensional (3D) computer aided design (CAD) models. In LS, a laser beam is used to selectively fuse or melt the polymer particles deposited in a thin layer and has the ability to produce complex geometries with accurate dimensions and good mechanical properties [1]. LS build parameters include laser power, scan spacing, part bed temperature, feed bed temperature, layer thickness, time between layers, number of scans, build size, roller speed and heating-cooling rates [1]. Results from other work indicated that the microstructure and the physical and mechanical properties of the laser-sintered parts are fundamentally affected by laser power, laser scan speed and laser scan spacing which are directly related to the amount of energy imparted on the powder surface in the part bed [2]. A limited range of polymer powders are viable for LS and mostly involves Polyamide 12 (Nylon 12) or other Polyamide based compounds [3] and in very few cases, Thermoplastic

*e-mail: y.khalil@sheffield.ac.uk
Elastomers (TPE) [4], Polycarbonate (PC) and Polystyrene (PS) [5]. However, new materials such Polypropylene (PP), Polyetherketone (PEEK) [4], High Density Polyethylene (HDPE) [6], Thermoplastic Polyurethane (TPU) [7], Polylactic acid (PLA) and Ultra High Molecular Weight Polyethylene (UHMWPE) [8] are currently showing increasing potential as LS materials.

\subsection{Ultra High Molecular Weight Polyethylene (UHMWPE)}

UHMWPE is a thermoplastic polymer that has excellent properties of wear resistance, self-lubrication, fatigue resistance, impact resistance, high chemical stability, resistance to low temperature and biocompatibility [9, 10]. UHMWPE is widely used in medical, industrial, military and consumer applications [11]. Due to its high molecular weight which induces a very high melt viscosity, UHMWPE parts cannot be produced easily by many conventional methods, such as extrusion and injection moulding, [12, 13]. UHMWPE is processed by ram extrusion and compression moulding [14] with a reported density of $0.936 \mathrm{~g} / \mathrm{cm}^{3}$, ultimate strength of $33.5 \mathrm{MPa}$ and elongation of $380.4 \%$ [15]. 
Limited attempts have been made to process UHMWPE by Additive Manufacturing (AM), specifically laser sintering. Rimell and Marquis [16] fabricated UHMWPE (GUR 4120 and GUR 4170) solid bodies using a non-commercial LS machine. Problems were encountered including material shrinkage and degradation. Goodridge et al. investigated the mechanical properties of the laser sintered UHMWPE (GUR 4170) parts, built on a Vanguard Laser Sintering machine (3D Systems), using three point bend test and tensile test [17]. They reported an average of Ultimate Tensile Strength and Young's modulus just above $0.2 \mathrm{MPa}$ and $1.5 \mathrm{GPa}$ respectively. However, sintered parts were only produced by using a precise combination of processing conditions.

In this study, UHMWPE laser-sintered tensile specimens were successfully fabricated using various laser power levels with significant sintering between particles and layers and also good mechanical properties.

\section{Materials characterization}

\subsection{UHMWPE powder}

The raw material used in the fabrication of the lasersintered parts was UHMWPE (GUR 2122) produced by Ticona, also known as Celanese, (Germany) with an average molecular weight of $4.5 \times 10^{6} \mathrm{~g} / \mathrm{mol}$ (Celanese GUR ${ }^{\circledR} 2122$ UHMWPE datasheet).

The average particle size of UHMWPE was $125 \mu \mathrm{m}$ and the statistical distribution ranges from $46.2 \mu \mathrm{m}$ to $293 \mu \mathrm{m}$, as measured by the laser scattering technique using Mastersizer 3000 (Malvern Instruments, UK) and dry sample dispersion technique.

Differential Scanning Calorimetry (DSC) was carried out using a PerkinElmer Pyris DSC 8500 at a heating and cooling rate of $10{ }^{\circ} \mathrm{C} / \mathrm{min}$. The powder was characterised for the melting and crystallisation behaviour and the DSC result was used to aid the determination of the required LS build temperature for the powder bed (i.e. super-cooling processing window). The DSC curve for un-sintered UHMWPE powder is shown in Figure 1. The melting temperature $\left(T_{\mathrm{m}}\right)$ and the peak for recrystallisation $\left(T_{\mathrm{c}}\right)$ of the UHMWPE is around $141{ }^{\circ} \mathrm{C}$ and $117^{\circ} \mathrm{C}$ respectively. The processing window for laser sintering of UHMWPE is extremely narrow.

\subsection{Manufacturing process}

The tensile test parts were designed according to the ASTM D638, type IV and were manufactured using a commercial laser sintering system (EOS P100, Germany). The dimensions of the width and thickness at the gauge length of $33 \mathrm{~mm}$ were $6 \mathrm{~mm}$ and $4 \mathrm{~mm}$ respectively while the overall length of the parts was $115 \mathrm{~mm}$. The tensile test parts were oriented in the $x-y$ direction with the long axis parallel to the $x$-axis (Figure 2). Four sets of test specimens (six parts specimens in each set) were fabricated using different laser powers of $6,8,10$ and $12 \mathrm{~W}$ and all other parameters including scan speed of $2500 \mathrm{~mm} / \mathrm{s}$, hatch spacing of $0.15 \mathrm{~mm}$, laser count of 2 (i.e. double scan), removal chamber temperature of

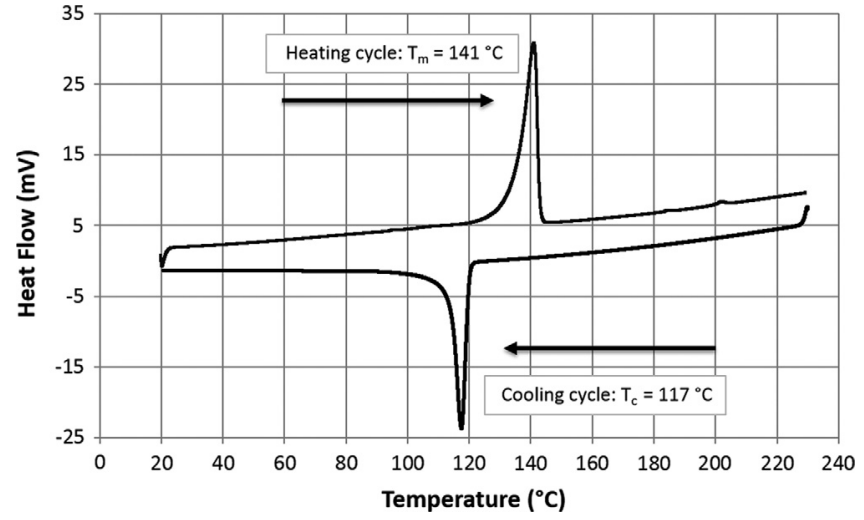

Figure 1. Differential scanning calorimetry (DSC) curve of UHMWPE powder.

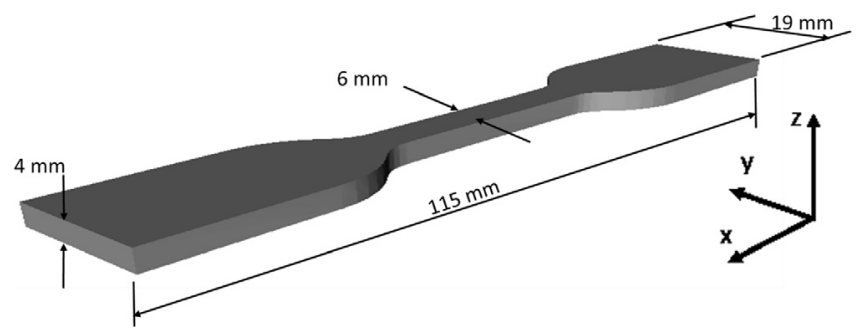

Figure 2. Schematic of the orientation of tensile test parts in the LS build bed.

$135{ }^{\circ} \mathrm{C}$ and powder bed temperature of $142{ }^{\circ} \mathrm{C}$ were kept constant. Although the bed temperature was a degree above the melting temperature of the powder, it was found to be suitable in terms of powder spreading and multilayers sintering. The selected temperature does not always represent the absolute thermodynamic temperature. A slight variation is expected in the actual temperature of the bed during the sintering process due to the variation in the emissivity of polymeric materials. Also, despite the fact that the recommended layer thickness needed to be larger than the average size of the powder particles, a layer thickness of $0.1 \mathrm{~mm}$ was selected for comparison purposes with Goodridge et al. work [17].

All parts were built without applying scale factors for compensation of the inherent shrinkage during cooling. After fabrication the parts were removed from the part cake and cleaned manually then sandblasting and pressurised air were used to remove any trace of un-sintered powder. The dimensions of the parts at the gauge length were taken at different locations using Vernier callipers, one at the centre and one at each end of the reduced width section. Each dimension was taken three times and an average of these values was recorded for each part.

\section{Evaluation of manufactured parts}

Relative density, dimensional accuracy, tensile properties and morphology of fracture surface were evaluated. 


\subsection{Relative density}

To determine the relative density ( $\left.\rho_{\text {Relative }}\right)$ of the UHMWPE sintered parts, the bulk density of these parts must be known. The bulk density ( $\rho_{\text {Bulk }}$ ) of LS parts was determined using equation (1). In this equation, $\rho\left(\mathrm{g} / \mathrm{cm}^{3}\right)$ represents the bulk density, $m(\mathrm{~g})$ is the mass and $v\left(\mathrm{~cm}^{3}\right)$ is the volume of the sintered part.

$$
\rho_{\text {Bulk }}=m / v
$$

The samples for density measurement were created by cutting out samples from rectangular LS parts with approximately $10 \mathrm{~mm}$ length, $9 \mathrm{~mm}$ width and $6.5 \mathrm{~mm}$ thickness. A sample size of three was used for each set of laser power. The mass of the density samples was determined by weighing the samples using a digital balance and the volume was determined using Vernier callipers measurement of dimensions.

The relative density, which is defined as the ratio of the bulk density of the parts to the true density $\left(\rho_{\text {True }}\right)$ of the material composing the parts (i.e. powder) was determined using equation (2).

$$
\rho_{\text {Relative }}=\left(\rho_{\text {Bulk }} / \rho_{\text {True }}\right) \times 100
$$

The true density of UHMWPE powder is $0.954 \mathrm{~g} / \mathrm{cm}^{3}$ as measured by helium gas pycnometer (Micromeritics AccuPyc II 1340, USA).

\subsection{Part dimensions}

In this study the influence of laser power on the dimensional accuracy of the parts produced was investigated. Measurements of the specimens' width and thickness at the gauge length were taken at different locations. Three measurements of each dimension were taken and an average value was then generated for each specimen. A sample size of six was used for each set and the average value of the part width and thickness was generated for each level of laser power.

\subsection{Tensile properties}

The tensile properties were directly measured using the sintered parts without any post processing beyond bead blasting and an average and range values obtained over five tests for each set of parameters. Tensile tests were performed on a tensile testing machine (Tinius Olsen Ltd, UK) fitted with a $1000 \mathrm{~N}$ load cell and laser extensometer. All the tests were carried out at ambient temperature with a constant cross head speed of $5 \mathrm{~mm} / \mathrm{min}$. Three measurements were made of the thickness and width at different locations using Vernier callipers, one at the centre and one at each end of the reduced width section (gauge length). The average of the three measurements was used when calculating the cross sectional area. The specimens were marked using two reflective tape strips at zero tension that are used to measure the elongation by the laser extensometer (Figure 3). Stress-strain data, Young's modulus, ultimate strength and elongation at break were generated by Tinius Olsen's Horizon software.

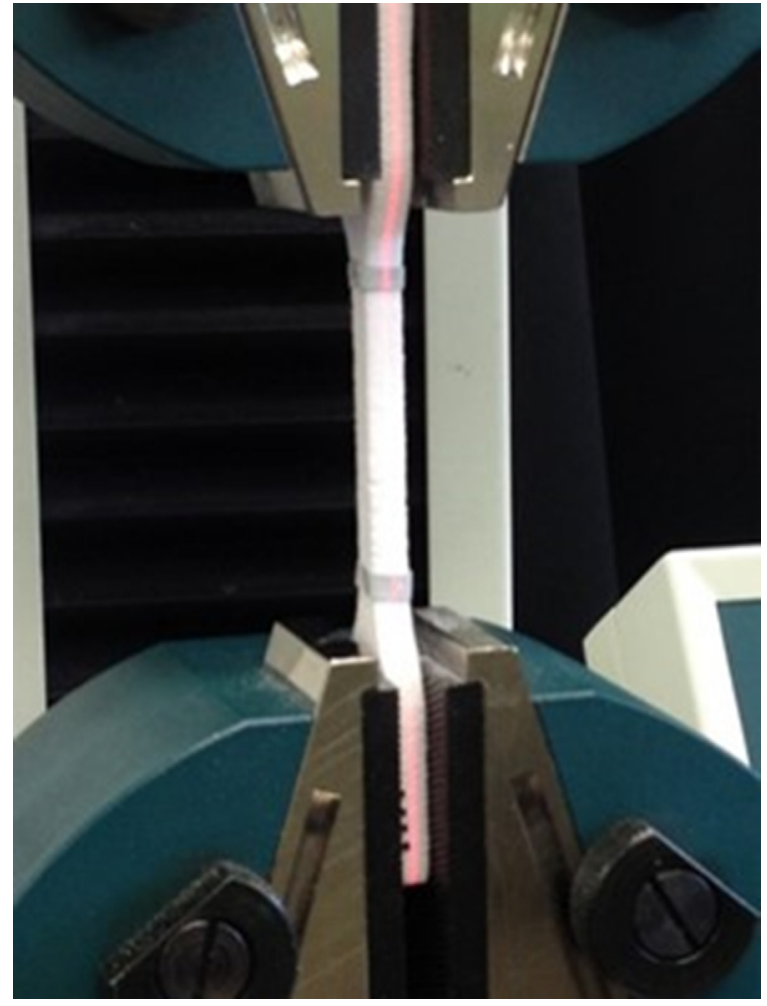

Figure 3. Tensile test specimen set up.

\subsection{Morphology of fracture surface}

The fracture morphology of the tensile test parts was observed using a scanning electron microscope (Philips XL-20, Holland) at an accelerating voltage of $15 \mathrm{kV}$. Samples were cut parallel to and $2-3 \mathrm{~mm}$ below the fracture surface. All samples were gold sputtered prior to observation.

\section{Results and discussion}

\subsection{UHMWPE sintered parts}

UHMWPE tensile test parts were successfully manufactured at laser powers of $6,8,10$ and $12 \mathrm{~W}$ and all parts were handled and cleaned without loss of definition (Figure 4).

\subsection{Relative density}

The relative density of the sintered parts was measured using equation (2) as detailed in Section 3.1. The influence of laser power on relative density of the sintered parts is shown in Figure 5.

The parts produced showed a notable change in relative densities with the change of laser power. The relative density of the sintered parts increased from $35 \%$ to $39 \%$ by increasing the laser power from $6 \mathrm{~W}$ to $10 \mathrm{~W}$. Further increase in the laser power resulted in a decreased relative density to $37 \%$ at laser power of $12 \mathrm{~W}$. 


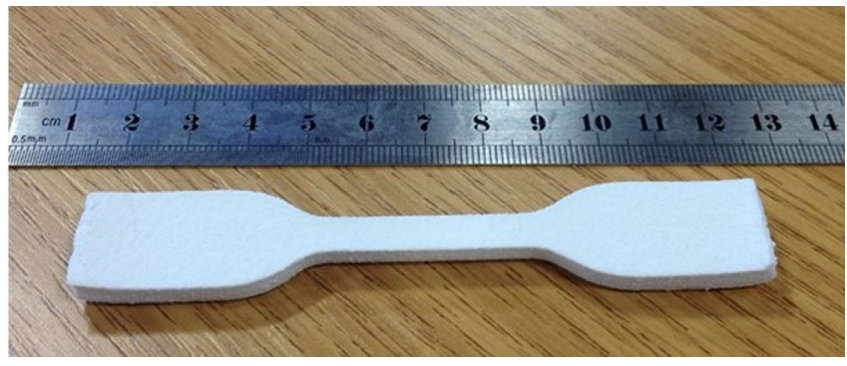

Figure 4. UHMWPE sintered part fabricated using $10 \mathrm{~W}$ laser power.

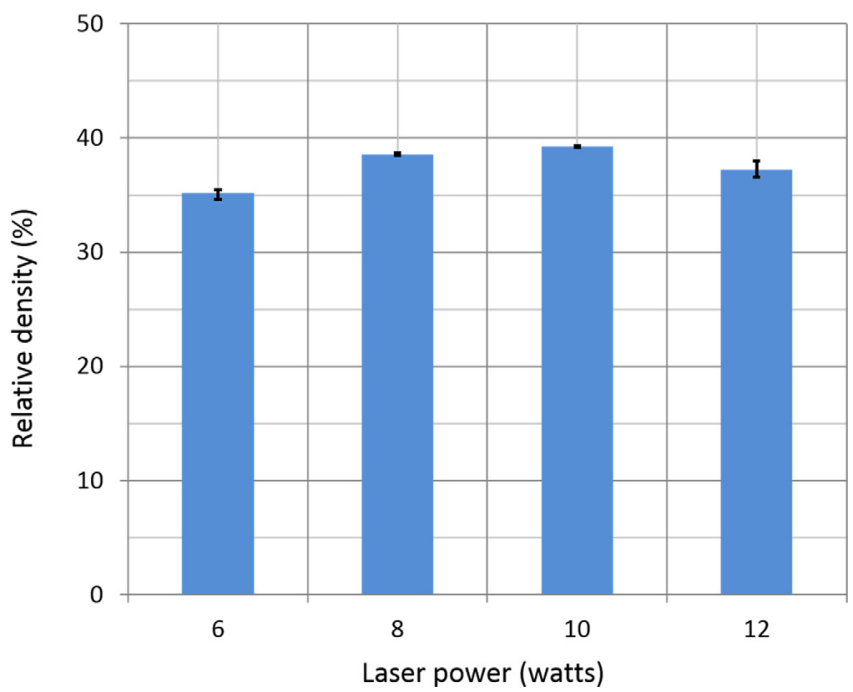

Figure 5. Average effect of laser power upon the relative density of the UHMWPE parts.

\subsection{Part dimensions}

Figure 6 shows the influence of laser power on the average dimensions. The average width achieved was between $5.54 \mathrm{~mm}$ and $5.87 \mathrm{~mm}$ with shrinkage in width between $0.13 \mathrm{~mm}$ and $0.46 \mathrm{~mm}$ compared to the original width dimension. Unlike the part width, the desired part thickness of $4 \mathrm{~mm}$ was exceeded for all laser powers and in the worst case was almost double the desired thickness. The average thickness achieved was between $4.83 \mathrm{~mm}$ and $6.99 \mathrm{~mm}$ with growth between $0.83 \mathrm{~mm}$ and $2.99 \mathrm{~mm}$ compared to the original thickness.

Figure 6 shows that there is no statistically significant difference in the width when the laser power is changed whilst the thickness of the parts show a notable decrease. The part width was slightly lower than the desired part width of $6 \mathrm{~mm}$ for all levels of laser power.

A small amount of shrinkage in the width is often observed. However, many factors may contribute to shrinkage but mainly including materials, process parameters, and the geometries of parts produced [18]. The dimensional variations are caused by inhomogeneous shrinkage which appears during the building and cooling processes which then leads to distortion in the sintered parts caused by stresses.

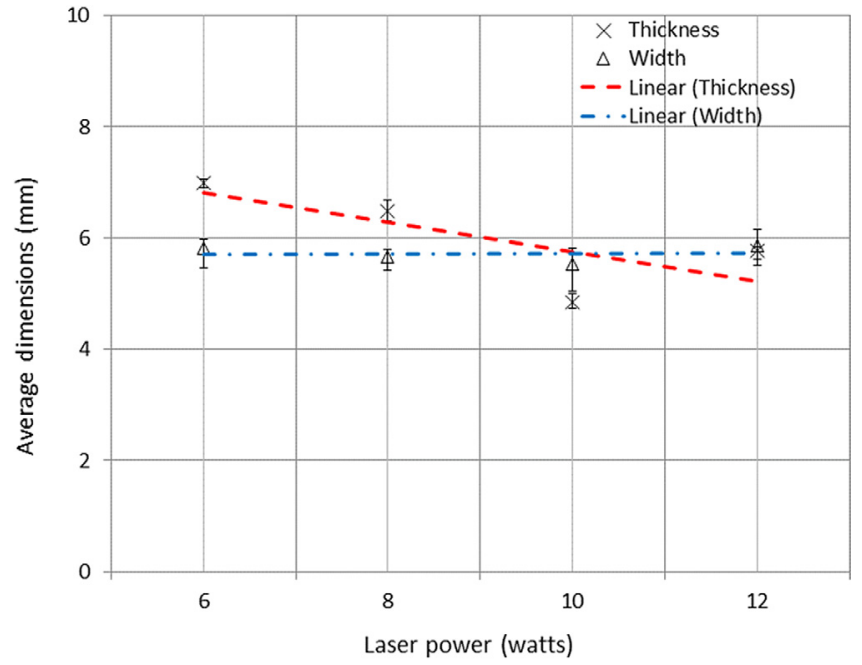

Figure 6. Dimension of UHMWPE parts fabricated by LS with different laser powers.

The shrinkage does not only depend on the temperature, at which the part is subjected to laser sintering, it is also affected by the length of time the powder bed retains heat, and also by the thickness of the powder layer [19].

In this work, a high growth was observed in the $z$-axis direction (i.e. thickness) which may occur due to thermal inconsistencies within the powder bed. Hopkinson and Sercombe found that error in $z$-axis direction is more apparent than in-plane errors. They suggested that this phenomenon is due to the heat generated by the laser which penetrates beyond the down facing surface to bond un-wanted particles which then leads to growth in $z$-axis direction [20].

\subsection{Tensile properties}

Tensile strength was measured to examine the influence of laser power. Observation during tensile test showed that considerable elongation took place before crack formation began and this behaviour is a classic example of ductile failure. Digital photographs of the specimens during the tensile tests are presented in Figure 7.

A crack was formed on the surface of the specimen before the breakage. The areas where the crack formation occurred are marked using red circles. The effect of laser power upon the tensile properties is shown in Table 1 including the average values for the ultimate strength, Young's modulus and elongation at break. The values of these properties for any given set of specimens were obtained by an average of five measurements and expressed as mean \pm standard deviation.

Stress-strain curves obtained by tensile test analysis are shown in Figure 8. The result revealed a less ductile behaviour for parts built at low laser powers than the parts built at higher laser power. When sintering at higher laser powers the bonds between the powder particles become stronger which leads to a more ductile behaviour with large plastic regions in the stress-strain curves as has been seen with LS of other polymers [21]. The parts built at the higher laser powers, 10 and $12 \mathrm{~W}$, 

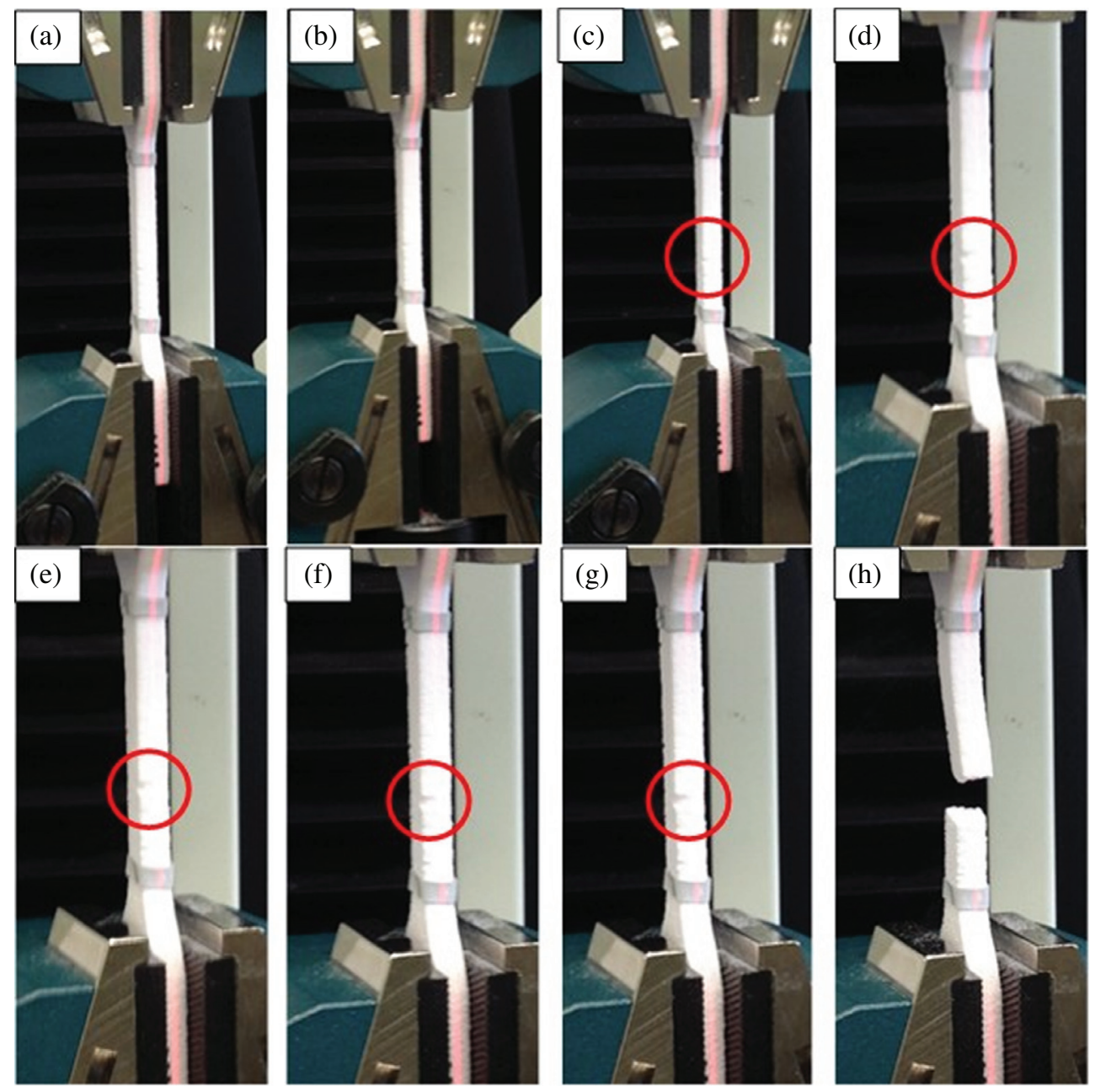

Figure 7. Tensile test of LS UHMWPE parts produced with laser power of $10 \mathrm{~W}$.

Table 1. Average tensile properties values of UHMWPE fabricated by LS parts.

\begin{tabular}{cccc}
\hline Laser power $(\mathrm{W})$ & Ultimate tensile strength $(\mathrm{MPa})$ & Young's modulus $(\mathrm{MPa})$ & Elongation at break $(\%)$ \\
\hline 6 & $1.63 \pm 0.13$ & $46.5 \pm 5.1$ & $35.6 \pm 6.3$ \\
8 & $1.69 \pm 0.06$ & $49.8 \pm 6.5$ & $42.2 \pm 4.6$ \\
10 & $2.42 \pm 0.20$ & $72.6 \pm 14.9$ & $51.4 \pm 6.6$ \\
12 & $1.93 \pm 0.10$ & $50.2 \pm 2.9$ & $50.6 \pm 6.9$ \\
\hline
\end{tabular}

showed a higher strength and modulus relative to the parts sintered at low laser powers, 6 and $8 \mathrm{~W}$.

Laser sintered UHMWPE parts showed an average value for ultimate strength of $1.63 \pm 0.13 \mathrm{MPa}$ which was achieved at laser power of $6 \mathrm{~W}$, while an average value of $2.42 \pm 0.20 \mathrm{MPa}$ was achieved at laser power of $10 \mathrm{~W}$ (Figure 8).

The low value for the ultimate strength provides evidence of the weak bonding between UHMWPE particles which is probably due to insufficient fusion. As the laser power increased to $12 \mathrm{~W}$ the UTS decreased. This phenomena was observed by Gill et al. and they reported that degradation of the polymer occurs with increasing laser energy density from the optimum, which then results in a reduction in strength [22]. Caulfield et al. observed similar phenomena with Nylon 12 (DuraForm $^{\mathrm{TM}}$ polyamide) and suggested this may be due to degradation of the polymer as a result of excessive exposure of the laser to the powder causing the particles to pyrolyse [21].

Figure 9 shows that the laser power used to create the parts had a strong influence on the resultant Young's modulus value.

The average value of the highest modulus was $72.6 \pm 14.9 \mathrm{MPa}$ at a laser power of $10 \mathrm{~W}$ while the average value of the lowest modulus was $46.5 \pm 5.1 \mathrm{MPa}$ at a laser power of $6 \mathrm{~W}$. 


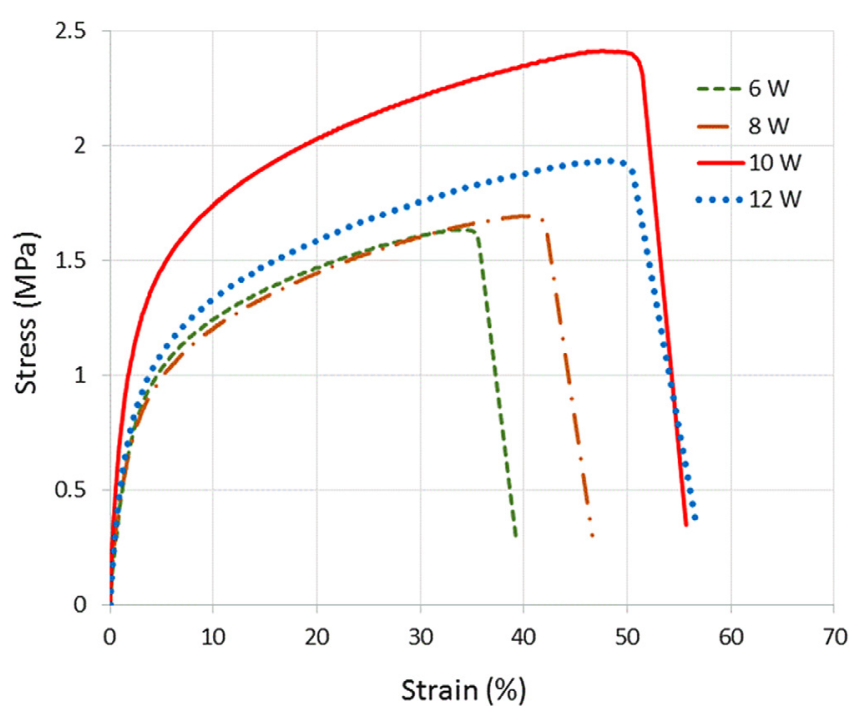

Figure 8. Stress-strain curves for each of the tested LP levels of the sintered par (each profile represent an average of 5 tested samples).

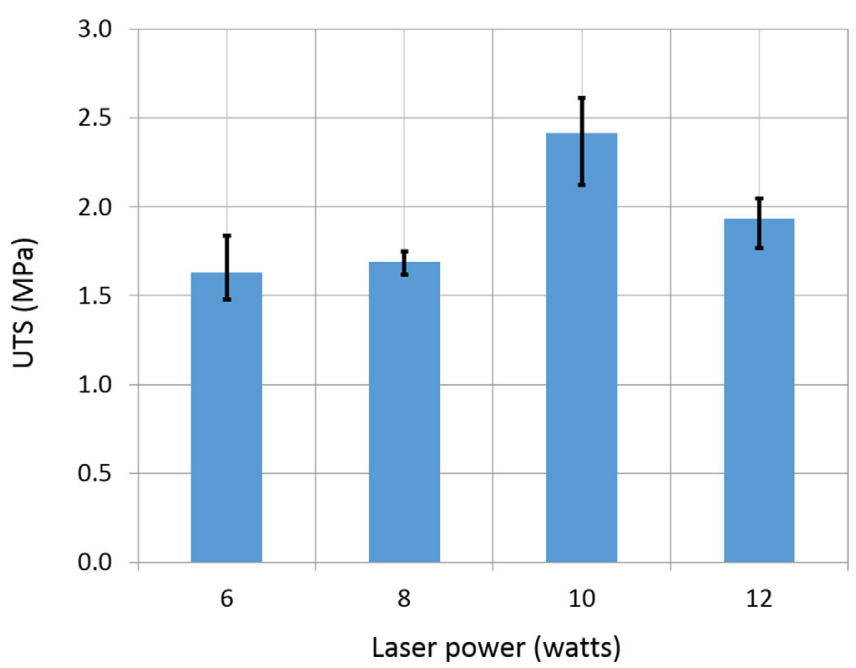

Figure 9. Effect of laser power on UTS of UHMWPE parts.

Average elongation at break ranges from 35.6 to $51.4 \%$. Figure 10 shows that the elongation increases with the increase in laser power and this can be attributed to the increase in part density and particle fusion [21]. This result shows that if the material integrity and interparticle bonding are enhanced by adequate laser power then the material ductility increases and the material becomes less brittle.

\subsection{Morphology of fracture surface}

The SEM micrographs of the fractured surfaces of the tensile test specimens at laser powers of $6,8,10$ and $12 \mathrm{~W}$ are shown in Figures $12-15$ respectively. A high degree

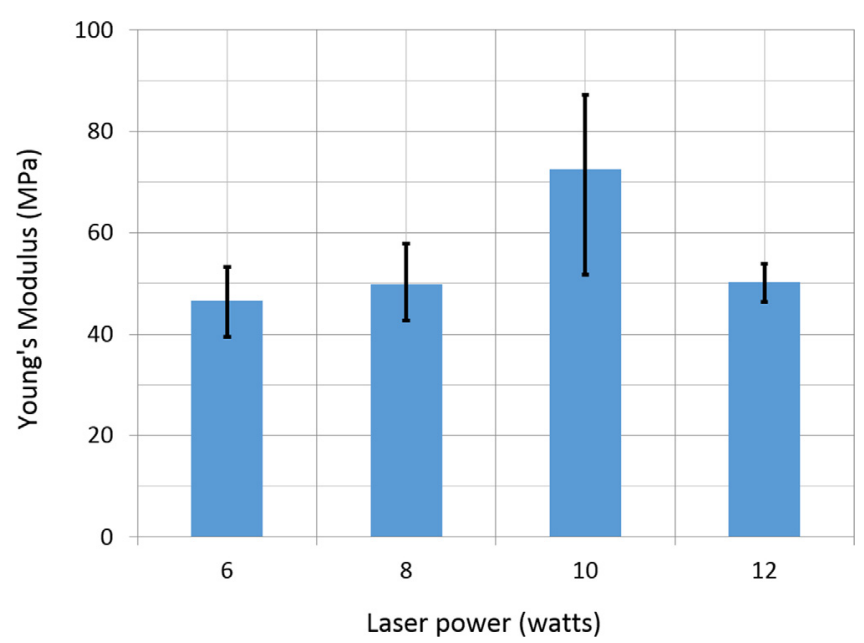

Figure 10. Effect of laser power on Young's modulus of UHMWPE parts.

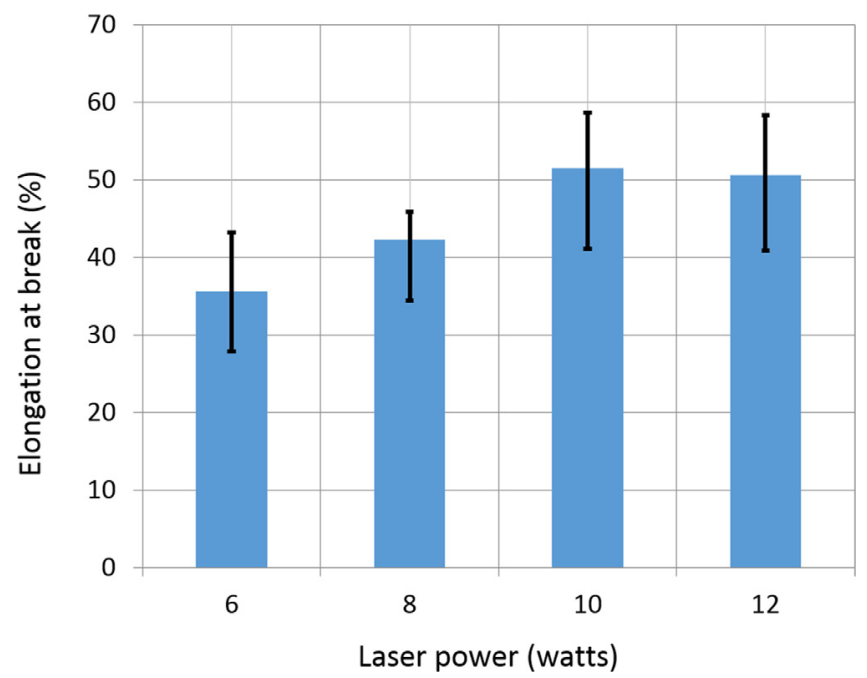

Figure 11. Effect of laser power on elongation at break of UHMWPE parts.

of sintering with large necks between the particles can be seen in all parts. The fracture surface micrographs show characteristic features of ductile failure with plastic deformation and fibrils on the surface which were produced by the separation of particles during the tensile test. The fibrils on the fracture surface of the parts laser sintered at $10 \mathrm{~W}$ were larger than those parts laser sintered at $6 \mathrm{~W}$ and corresponded to the higher elongation at break of the $10 \mathrm{~W}$ parts. Referring to Section 4.3, during tensile test cracks were formed on the surface of the specimen before the breakage. Crack initiation is normally followed by crack growth in which more fibrils undergo extensive plastic deformation until they rupture. This is evident from all micrographs. 

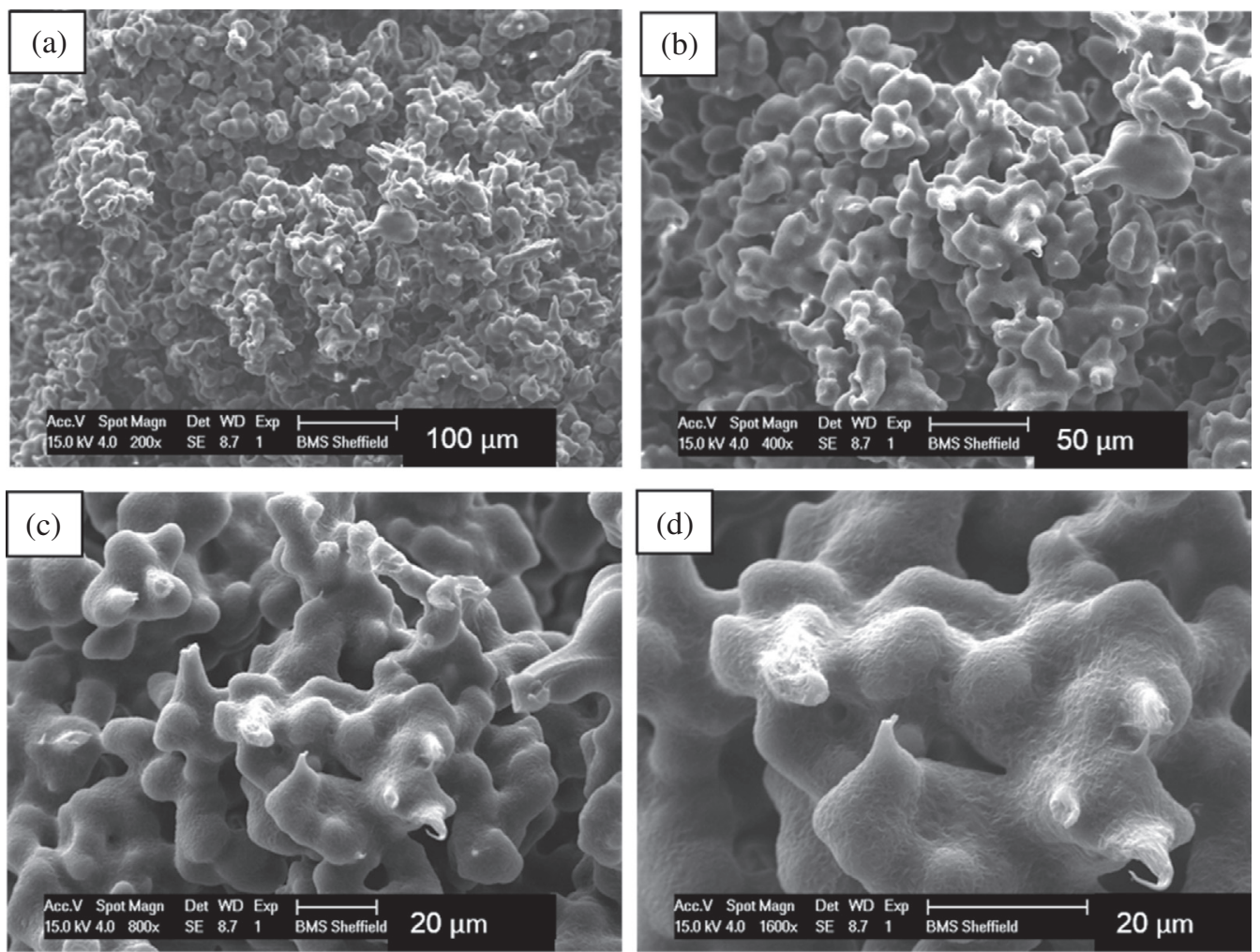

Figure 12. SEM micrographs of the fracture surface of tensile tested part of UHMWPE at $6 \mathrm{~W}$ with magnifications: (a) 200×, (b) 400×, (c) $800 \times$ and (d) $1600 \times$.
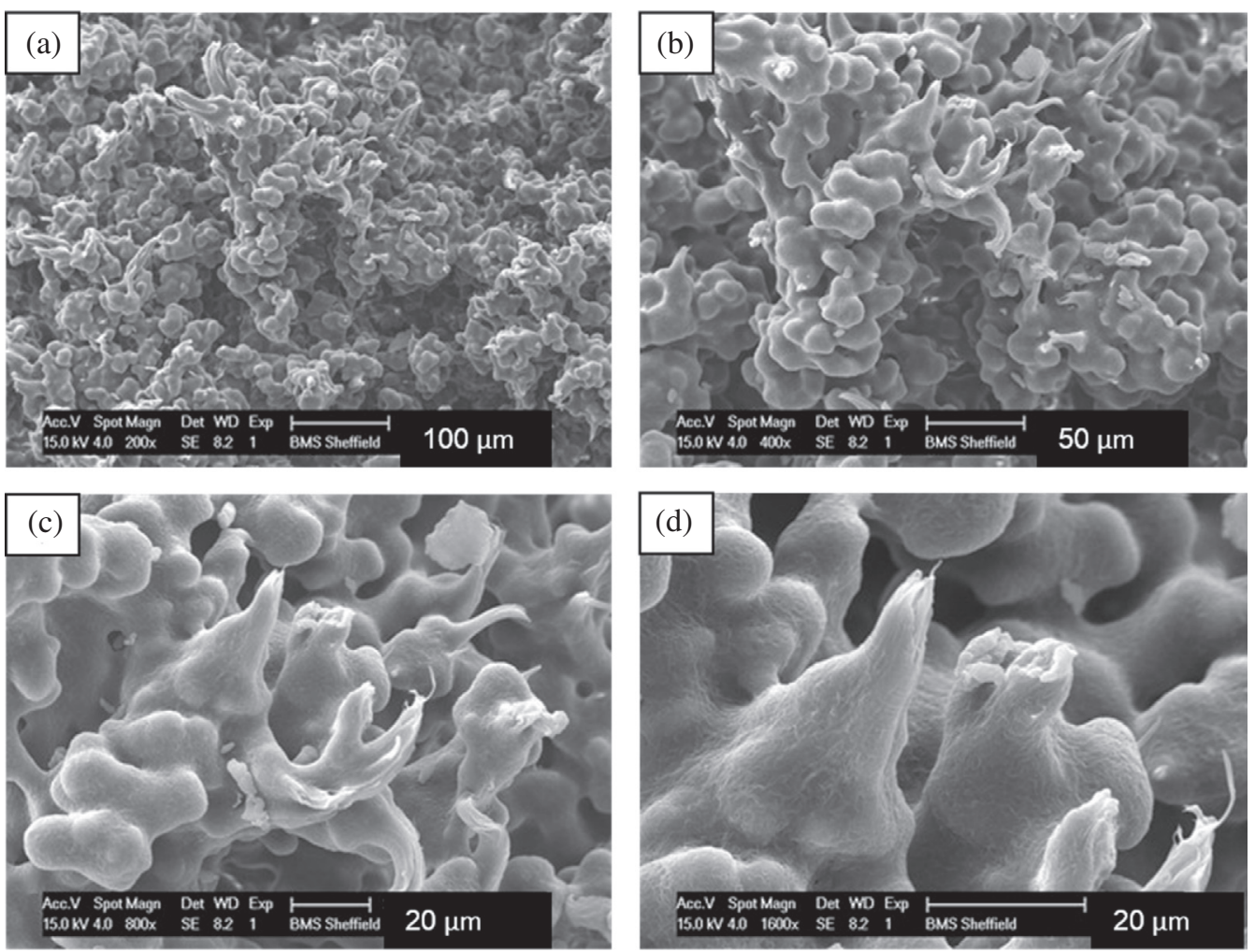

Figure 13. SEM micrographs of the fracture surface of tensile tested part of UHMWPE at $8 \mathrm{~W}$ with magnifications: (a) 200×, (b) 400×, (c) $800 \times$ and (d) $1600 \times$. 

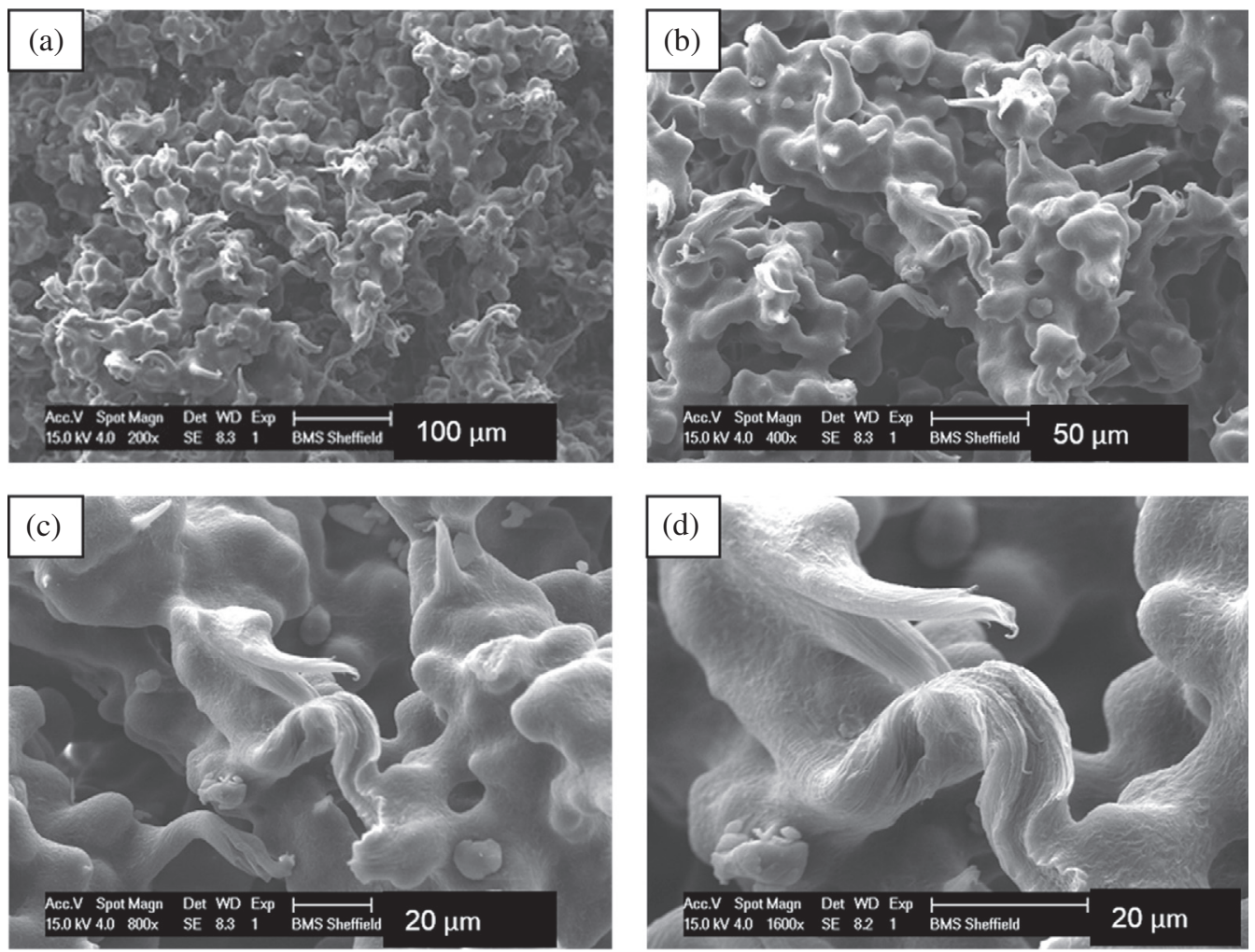

Figure 14. SEM micrographs of the fracture surface of tensile tested part of UHMWPE at $10 \mathrm{~W}$ with magnifications: (a) $200 \times$, (b) $400 \times$, (c) $800 \times$ and (d) $1600 \times$.
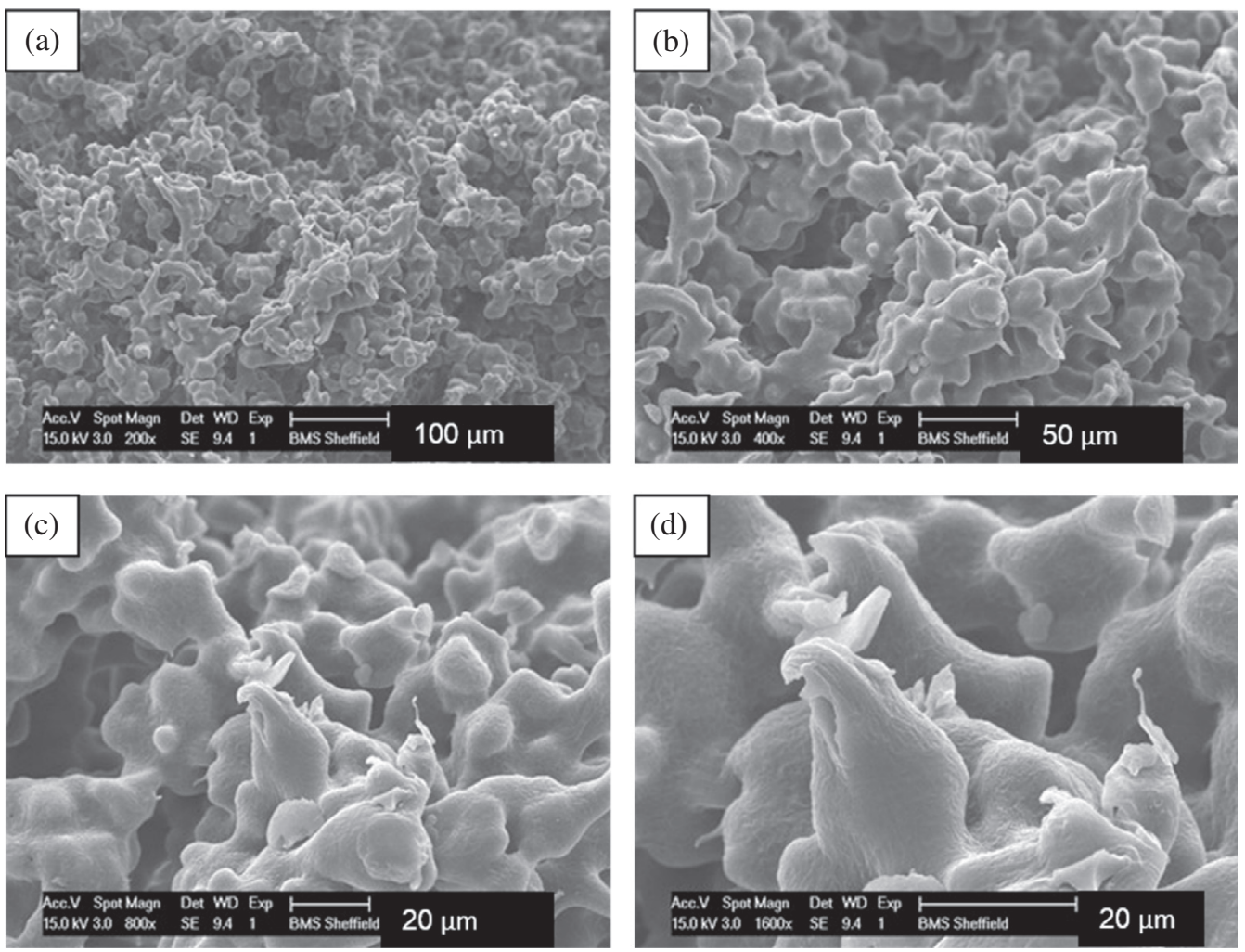

Figure 15. SEM micrographs of the fracture surface of tensile tested part of UHMWPE at $12 \mathrm{~W}$ with magnifications: (a) $200 \times$, (b) $400 \times$, (c) $800 \times$ and (d) $1600 \times$. 


\section{Conclusions}

Tensile test parts of UHMWPE were successfully manufactured by Laser Sintering across a range of build parameters. The sintered parts were mechanically tested at room temperature. The three mechanical parameters investigated, ultimate strength, modulus and elongation, exhibit a clear dependence on the sintering laser power. Minimum ultimate tensile strength of $1.63 \pm 0.13 \mathrm{MPa}$ was achieved at laser power of $6 \mathrm{~W}$ while a maximum of $2.42 \pm 0.20 \mathrm{MPa}$ was achieved at $10 \mathrm{~W}$. The same trend was reflected in the Young's modulus with average values in range between $46.5 \pm 5.1$ and $72.6 \pm 14.9 \mathrm{MPa}$ at laser powers of 6 and $10 \mathrm{~W}$ respectively. Maximum elongation of $51.4 \% \pm 6.6$ was achieved at laser power of $10 \mathrm{~W}$. The sintered parts achieved relative density in range between $35 \%$ and $39 \%$ which indicated a high porosity structure formed by the laser sintering. The average width of the laser sintered parts was between $5.54 \mathrm{~mm}$ and $5.87 \mathrm{~mm}$ with shrinkage in width between $0.13 \mathrm{~mm}$ and $0.46 \mathrm{~mm}$ and this indicates that there is no statistically significant difference when laser power is changed. However, the part thickness of $4 \mathrm{~mm}$ was exceeded for all laser powers and the average thickness observed was between $4.83 \mathrm{~mm}$ and $6.99 \mathrm{~mm}$ with a growth between $0.83 \mathrm{~mm}$ and $2.99 \mathrm{~mm}$.

Acknowledgements. The authors would like to acknowledge the research funding from the Engineering and Physical Sciences Research Council (EPSRC) of Great Britain (Grant Number EP/ M507611/1). The authors also would like to thank Mr. Peter Burke from Ticona GmbH (Celanese, Germany) for the generous supply of the UHMWPE powder. Further contribution from the industrial sponsor (Unilever PLC, UK) is also acknowledged with appreciation.

\section{References}

1. D.L. Bourell, T.J. Watt, D.K. Leigh, B. Fulcher, Physics Procedia 56 (2014) 147-156.

2. M.M. Savalani, L. Hao, Y. Zhang, K.E. Tanner, R.A. Harris, Proceedings of the Institution of Mechanical Engineers H 221 (2007) 873-886.

3. A. Amado, M. Schmid, G. Levy, K. Wegener, Proceedings SFF Symposium, Austin, Texas, 2011, pp. 438-452.

4. D. Drummer, D. Rietzel, F. Kühnlein Physics Procedia Part B 5 (2010) 533-542.
5. J.-P. Kruth, G. Levy, R. Schindel, T. Craeghs, E. Yasa, Consolidation of polymer powders by selective laser sintering, PMI International Conference, Ghent, Belgium, 2008, pp. $1-16$.

6. G.V. Salmoria, C.H. Ahrens, P. Klauss, R.A. Paggi, R.G. Oliveira, A. Lago, Materials Research 10 (2007) 211-214.

7. S. Ziegelmeier, P. Christou, F. Wöllecke, C. Tuck, R. Goodridge, R. Hague, E. Krampe, E. Wintermantel, Journal of Materials Processing Technology 215 (2015) 239-250.

8. R.D. Goodridge, C.J. Tuck, R.J.M. Hague, Progress in Materials Science 57 (2012) 229-267.

9. S.M. Kurtz, UHMWPE biomaterials handbook: ultra high molecular weight polyethylene in total joint replacement and medical devices, Academic Press, 2009.

10. A.D.A. Lucas, J.D. Ambrósio, H. Otaguro, L.C. Costa, J.A.M. Agnelli, Wear 270 (2011) 576-583.

11. Q. Zhang, M. Jia, P. Xue, Journal of Applied Polymer Science 126 (2012) 1406-1415.

12. D. Jauffrès, O. Lame, G. Vigier, F. Doré, Polymer 48 (2007) 6374-6383.

13. X. Liang, X. Wu, K. Zeng, B. Xu, S. Wu, H. Zhao, B. Li, S. Ruan, Journal of Micromechanics and Microengineering 24 (2014) 045014.

14. M.B. Turell, A. Bellare, Biomaterials 25 (2004) 3389-3398.

15. S.V. Panin, L. Kornienko, M.A. Poltaranin, L.R. Ivanova, S.V. Shilko, Role of micro-and nanofillers in abrasive wear of composites based on ultra-high molecular weight polyethylene, Advanced Materials Research (Trans Tech Publications, 2014), pp. $148-154$.

16. J.T. Rimell, P.M. Marquis, Journal of Biomedical Materials Research 53 (2000) 414-420.

17. R.D. Goodridge, R.J.M. Hague, C.J. Tuck, Journal of Materials Processing Technology 210 (2010) 72-80.

18. K. Senthilkumaran, P.M. Pandey, P.V.M. Rao, Materials \& Design 30 (2009) 2946-2954.

19. K. Manetsberger, J. Shen, J. Muellers, Solid Freeform Fabrication Symposium, Austin, Texas, 2001, pp. 221-232.

20. N. Hopkinson, T.B. Sercombe, Rapid Prototyping Journal 14 (2008) 108-113.

21. B. Caulfield, P.E. McHugh, S. Lohfeld, Journal of Materials Processing Technology 182 (2007) 477-488.

22. T.J. Gill, K.K.B. Hon, Proceedings of the Institution of Mechanical Engineers, Part B: Journal of Engineering Manufacture 218 (2004) 1249-1256.

Cite this article as: Khalil Y, Kowalski A \& Hopkinson N: Influence of laser power on tensile properties and material characteristics of laser-sintered UHMWPE. Manufacturing Rev. 2016, 3, 15. 